\title{
Ventricular Premature Complex by ECG
}

\section{Finding}

National Cancer Institute

\section{Source}

National Cancer Institute. Ventricular Premature Complex by ECG Finding. NCI

Thesaurus. Code C62256.

An electrocardiographic finding of an ectopic impulse originating in the ventricles. The QRS morphology of these complexes is different from those of supraventricular origin. The QRS duration is often longer and the RR interval preceding the complexes is usually shorter than that of supraventricular beats. (CDISC) 